Article

\title{
The Recognition of the Micro-Events in Cement Composites and the Identification of the Destruction Process Using Acoustic Emission and Sound Spectrum
}

\author{
Dominik Logoń *(1) and Krzysztof Schabowicz \\ Faculty of Civil Engineering, Wrocław University of Science and Technology, Wybrzeże Wyspiańskiego 27, \\ 50-370 Wrocław, Poland; krzysztof.schabowicz@pwr.edu.pl \\ * Correspondence: dominik.logon@pwr.edu.pl
}

Received: 8 June 2020; Accepted: 1 July 2020; Published: 4 July 2020

check for updates

\begin{abstract}
This paper presents the recognition of micro-events and their concentration in quasi-brittle cement composites and the identification of the destruction process based on acoustic emission and sound spectrum. The tests were conducted on a quasi-brittle composite of a cement paste reinforced with a high volume of dispersed polypropylene fibers. The possibility of identifying the destruction process based on acoustic emission and sound spectrum was confirmed. This paper focused on the identification of micro-events using the 3D spectrum. It was shown that the identification of the concentration of micro-events precedes the occurrence of critical crack $f_{c r}$, ending the Hooke's law range. The ability to recognize this phenomenon with the use of the 3D spectrum makes it possible to predict the structure destruction process and subsequently to assess the structure destruction (micro and macro-cracks) and the reinforcement destruction (pull-off, breaking). It was confirmed that the three-dimensional spectrum provided additional information, enabling a better recognition of micro and macro-changes in the structure of the samples based on the analysis of sound intensity, amplitudes, and frequencies.
\end{abstract}

Keywords: quasi-brittle cement composites; acoustic emission; acoustic spectrum; micro events

\section{Introduction}

Acoustic emission (AE) is a method that has been used for a very long time in concrete engineering [1]. Acoustic emission measurements can be applied to recognize the early hydration of cement [2,3]. Most papers have focused on determining the destruction process (cracks, maximum load, and failure of reinforcement in cement composites) [4-40]. It was noticed that $\mathrm{AE}$ is an effective method in determining the critical stress $\mathrm{f}_{\mathrm{cr}}$ of cement composites corresponding to the first crack [4-6]. It is used for the accurate definition of the elastic range corresponding to Hooke's law [7,8]. The continuous $\mathrm{AE}$ evaluation in composites and acoustic emission AE events sum (sum AE) has been applied to determine the first crack $[4,9,10]$, micro and macro-cracks, and their propagation in the fracture process in cement composites with [11,12] and without reinforcement $[13,14]$.

The test results indicate that $\mathrm{AE}$ is a good method for crack formation monitoring in mechanically loaded traditional $[15,16]$ and high strength $[17,18]$ cement composites. It was demonstrated that this method is effective during compression [19,20] and bending tests [21,22].

Acoustic emission measurements also focus on the possibility of identifying crack orientation [23-25] $q$, thus enabling the recognition of cracks occurring as a result of compression, tensile, and shear stress.

$\mathrm{AE}$ is used to identify the destruction process of different materials (e.g., reinforced geopolymer mortars) [26]. The effectiveness of acoustic emission measurements in structures control was 
confirmed [27-29]. This method is used for example to monitor and control bridges condition [30,31]. The AE is still improved for the purpose of the identification of failure processes in different materials and structures [32-34].

Our previous own works have focused on the correlation between $\mathrm{AE}$ and the individual failure processes of each of the different composite components based on the sound spectrum $[7,35,36]$. The conclusions indicate that for the accurate recognition of composite failure processes, the $\mathrm{AE}$ recording should be expanded to include the analysis of each sound separately (also a single signal in a very small range of frequencies) and the analysis of the range of sounds corresponding to a given mechanical effect with the use of acoustic spectrum. It was noticed that the acoustic spectrum 2D and 3D should be correlated with the load-deflection curve and with other acoustic effects, which enables the identification of the failure process.

The presented paper confirms that there is a possibility of correlation between $\mathrm{AE}$ and the failure process in quasi-brittle cement composites. This correlation enables a determination of the stage of damage in cement composites, increasing the safety of using the composite and a decision whether or not the damaged composite can be repaired.

The main innovation of this research is the possibility of identifying AE micro events in the area preceding the occurrence of critical crack initiating the destruction process in cement composites. The main idea in this paper is the possibility of micro event recognition in the Hooke's law range, which enables the prediction of the destruction process.

The paper presents the results of our own studies on a selected paste sample in a four-point bending tensile test conducted at IPPT PAN in Warsaw, taking into consideration the current recommendations [37-41].

The results of tests carried out on a number of cement composites (cement paste, mortar, concrete, with and without dispersed reinforcement [40]) confirmed the general conclusions presented in the paper, indicating the possibility of their generalization.

\section{Testing}

\subsection{Materials Used for Tests}

High-strength cement composites w/(c + Sf) $=0.31$, Portland Cement CEM I 42.5R (c), silica fume $\mathrm{S}_{\mathrm{f}}=10 \% \mathrm{c}$, siliceous fly ash $20 \% \mathrm{c}$, superplasticizer Sp, tap water $(\mathrm{w})$.

Synthetic-structural polypropylene fibers (ASTM C-1116): density $0.91 \mathrm{~kg} / \mathrm{dm}^{3}, \mathrm{f}_{\mathrm{t}}=620-758 \mathrm{MPa}$, $\mathrm{E}=4.9 \mathrm{GPa}, \mathrm{l}=54 \mathrm{~mm}, \mathrm{~d}=0.48 \mathrm{~mm}, 1 / \mathrm{d}=113$.

The specimens were reinforced with a polypropylene fiber volume of $V_{f}=5 \%$. The samples with dimensions $40 \times 40 \times 160 \mathrm{~mm}$ were cut out from pre-formed slabs. Each beam was turned by $90^{\circ}$ and cut to the depth of $7 \mathrm{~mm}$.

\subsection{Preparation of Specimens for Tests}

Four-point bending tensile tests were carried out at IPPT PAN in Warsaw [40]. The measurements were conducted on sample beams with the dimensions of $40 \times 40 \times 160 \mathrm{~mm}$ (Figure 1). In the middle of the span, in the lower part, a cut ( $7 \mathrm{~mm}$ deep) was made in the specimens, in accordance with American Society for Testing and Materials ASTM 1018 [37]. This paper presents the results for quasi-brittle cement composite of paste with high volume of polypropylene fiber reinforcement.

\subsection{Description of the Test Stand}

The tests were conducted on three specimens. The results obtained for each of the three specimens separately confirm the conclusions contained in the paper. 

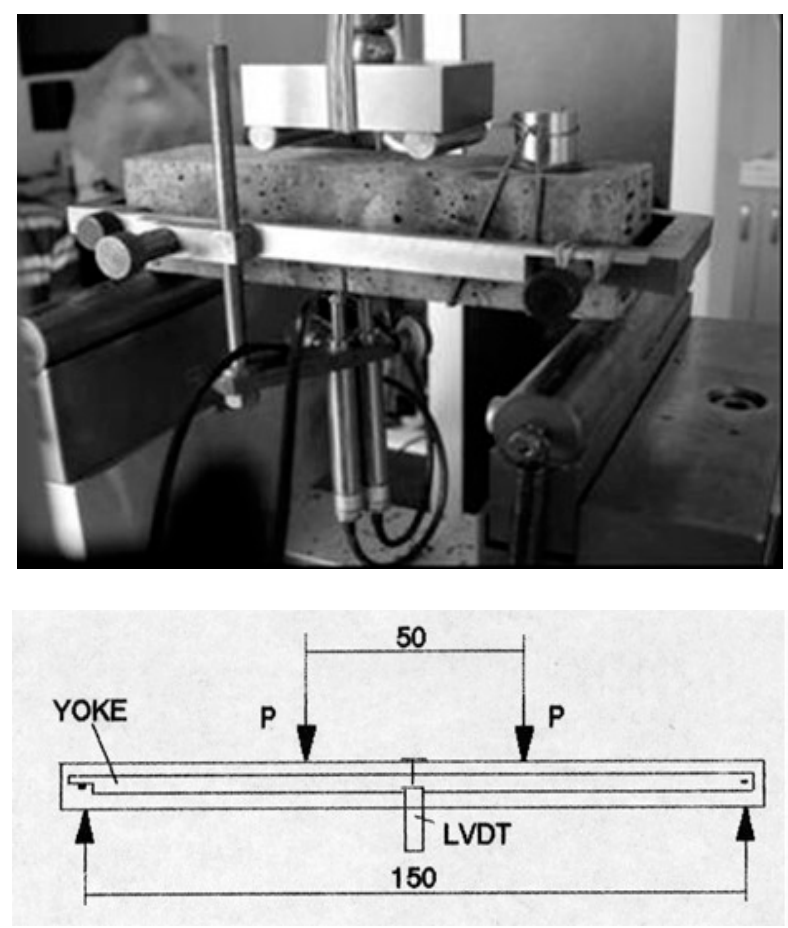

Figure 1. Four-point bending test [40].

The loading process was carried out with a controlled, constant displacement speed equaling $0.05 \mathrm{~mm} / \mathrm{min}$. Deflection was recorded by means of two LVDT sensors located under the beam, using a "Yoke" clamp (Figure 2), [40]. During the test, the bending load and deflection of the specimen were measured. The testing procedure corresponded to the requirements of the ASTM C 1018 standard.

At the end of the test, a $5 \mathrm{~mm}$ deflection of the specimens was recognized, which was determined in relation to the neutral axis. The acoustic emission sensor was fixed to the top surface of the beams with the use of an elastic band and the surface was coated with coupling graphite grease (Figure 1).

The broadband AE sensor manufactured by Physical Acoustic Corp. enabled the recording of the AE signal within the frequency range of $10-1000 \mathrm{kHz}$.

The AE signal was recorded with the use of the ADLINK 9112 card with the sampling rate of $88.2 \mathrm{kHz}$, the 12-bit resolution, and the function of a continuous recording on a computer disk. Source files were saved in the format (.wav), which makes it possible to listen to the recorded signal with the use of the computer sound card speakers.

Thanks to the recorded data, it is possible to plot a load-deflection curve, record AE events, and aggregate them (total AE).

The acoustic emission effects were presented as a 2D and 3D acoustic spectrum (amplitude of the frequency depending on sound intensity). The 2D sound spectrum was achieved with the use of the Audacity program and the 3D spectrum using SpectraPLUS-SC (Pioneer Hill Software LLC, Poulsbo, WA, USA).

The quasi-brittle cement composites (ESD-Eng. elastic range, strengthening control, deflection control) were characterized by higher load and absorbed energy in the elastic range compared to the sample without reinforcement (Figure 2) [35]. The reinforcement effects may be presented by characteristic points $f_{x}$ ( $F_{x}$-load, $\varepsilon_{x}$-deflection, $W_{x}$-work) and areas $A_{X}$ under the load-deflection curve.

Figure 2 presents the mechanical effects of the quasi-brittle cement composites with the corresponding acoustic effects and compiled acoustic spectra with various amplitudes corresponding to different mechanical effects (reinforcement breaking, pull-out, macrocracks, microcracking, and micro-events). 
a)
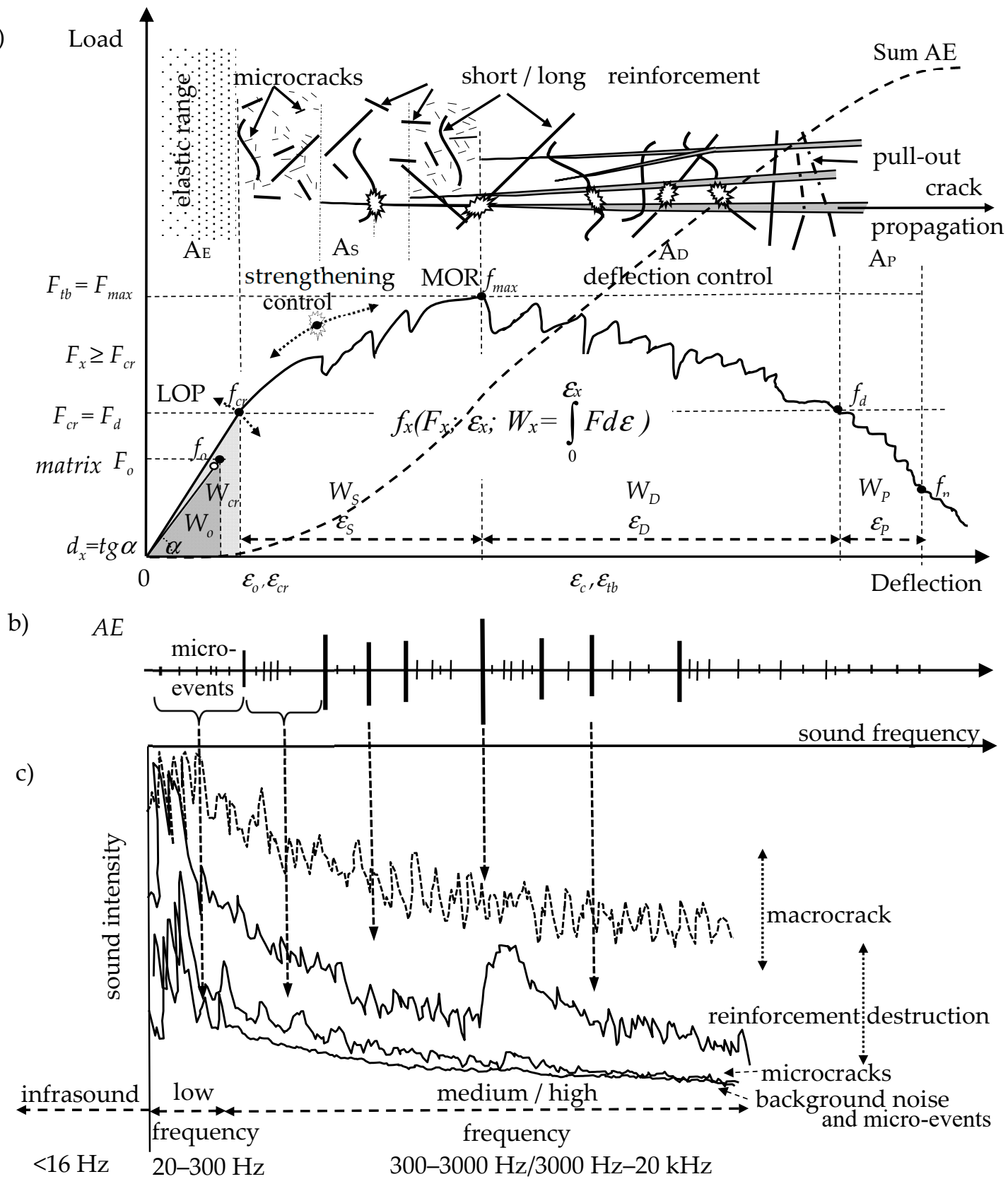

Figure 2. The quasi-brittle composite: (a) load-deflection curve, (b) AE, acoustic emission effects, (c) 2D acoustic spectrum (frequency amplitude depending on sound intensity) based on [36].

\section{Test Results}

The results are presented using the example of a quasi-brittle cement composite of slurry type with dispersed reinforcement in the form of structural polypropylene fibers (Figures 3 and 4).

In the top part of Figure 3, the recording of AE effects is presented. The figure shows charts from four-point bending tensile tests, force-deflection, and force-time; in addition, it shows the recorded events as a function of time (0-160 s) and the AE events total. 


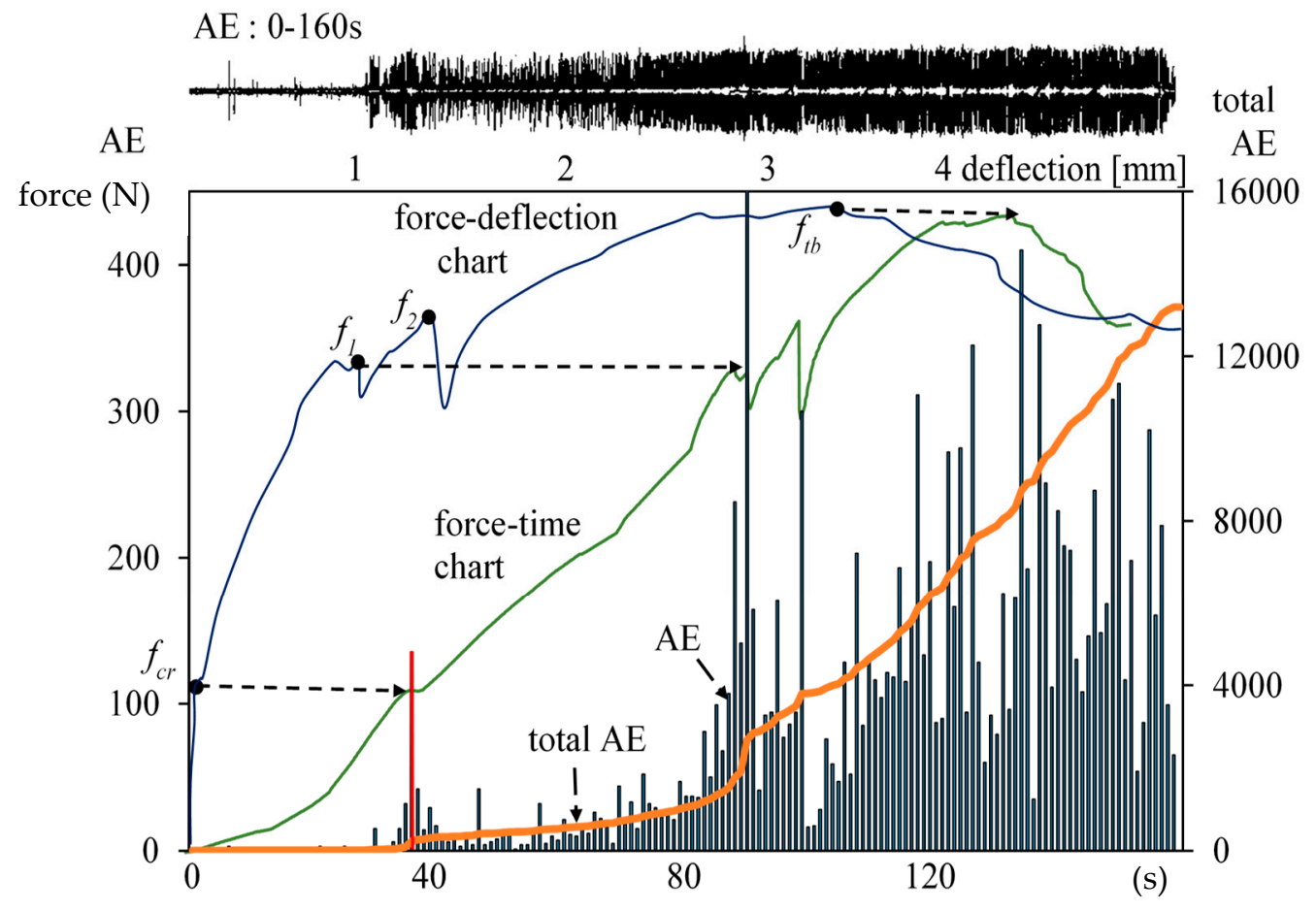

Figure 3. Results of tests on the composite in the range of 0-160 s: force-deflection, force-time curve, total acoustic emission $\mathrm{AE}$, events, and $\mathrm{AE}$ recording.

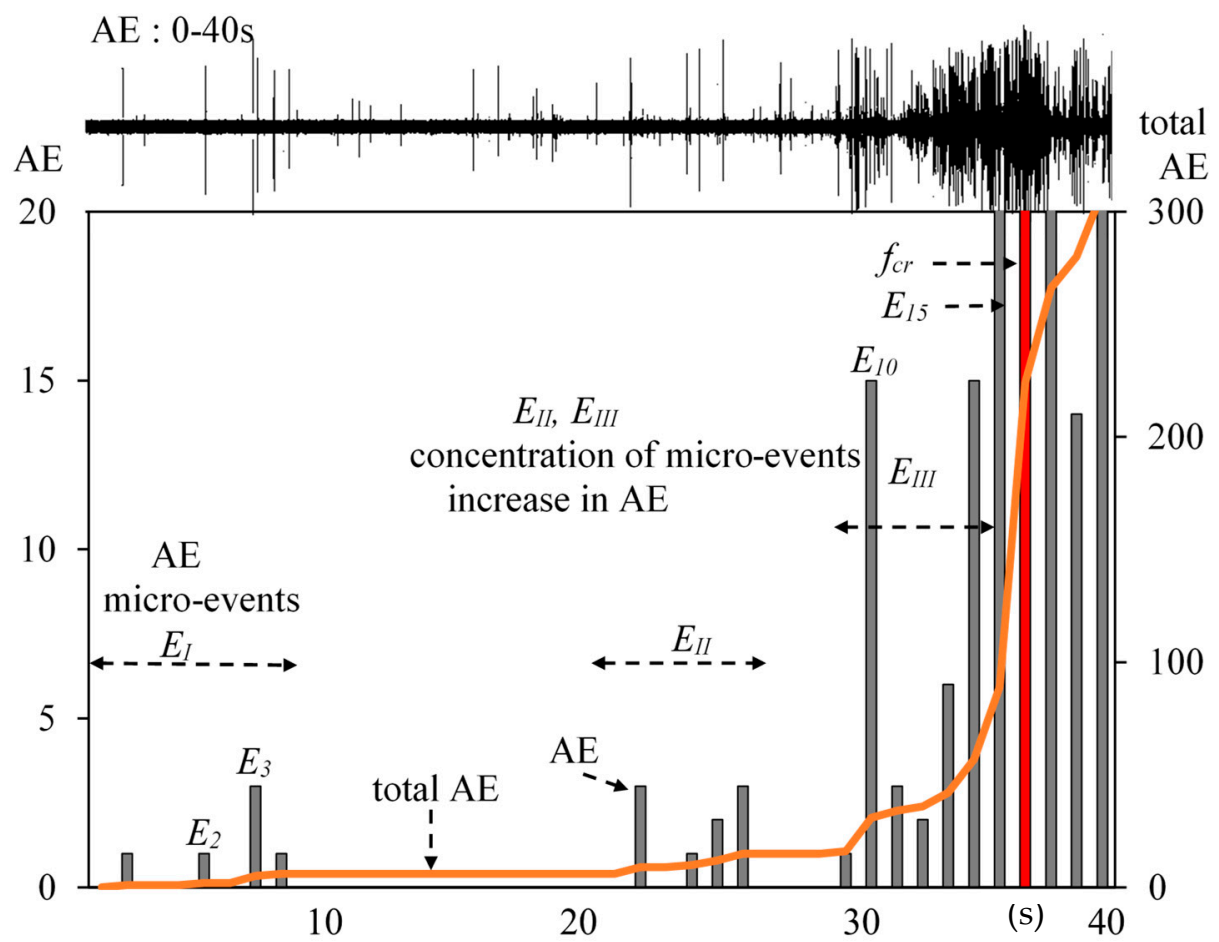

Figure 4. Results of tests on the composite Figure 1 in the range of $0-40 \mathrm{~s}$ : total AE, events, and AE recording. 
The characteristic points and ranges of $\mathrm{AE}$ events are highlighted in the presented figure. In addition, the chart of total $\mathrm{AE}$ is shown. The red color marks the event $\mathrm{f}_{\mathrm{cr}}$ (the end of Hooke's law), corresponding to the critical point $f_{\text {cr }}$ on the force-deflection curve. Point $f_{1}$ corresponds to the sudden drop in stress in the strengthening area, and point $\mathrm{f}_{\mathrm{tb}}$ corresponds to maximum stress.

In order to analyze the destruction process in the proportionality area shown in Figure 3, the effects obtained in that range of deflections (in the range of $0-40 \mathrm{~s}$ ) were enlarged and presented in Figure 4.

The spectrogram of the AE signal of the tested composite is presented in Figure 5. Events are visible as vertical lines with marked characteristic points $\mathrm{f}_{\mathrm{cr}}, \mathrm{f}_{1}, \mathrm{f}_{\mathrm{tb}}$, and image of events occurring in quasi-brittle composites, with highlighted areas of proportionality $\mathrm{A}_{\mathrm{E}}$, strengthening control $\mathrm{A}_{\mathrm{S}}$ and deflection control $A_{D}$. The area with a dominating impact of event noise as well as the areas with the concentration of events $\mathrm{E}_{\mathrm{II}}$ and $\mathrm{E}_{\mathrm{III}}$ are marked. The spectrum is presented in the range of low, medium, and high frequency from $0-4000 \mathrm{~Hz}$. The red intermittent line in the spectrogram marks an area that is linked to the possible occurrence of dispersed reinforcement breaking. Figure 5 enables the observation of the concentration of micro-events preceding $\mathrm{f}_{\mathrm{cr}}\left(\mathrm{E}_{\mathrm{II}}\right.$ and $\left.\mathrm{E}_{\mathrm{III}}\right)$.

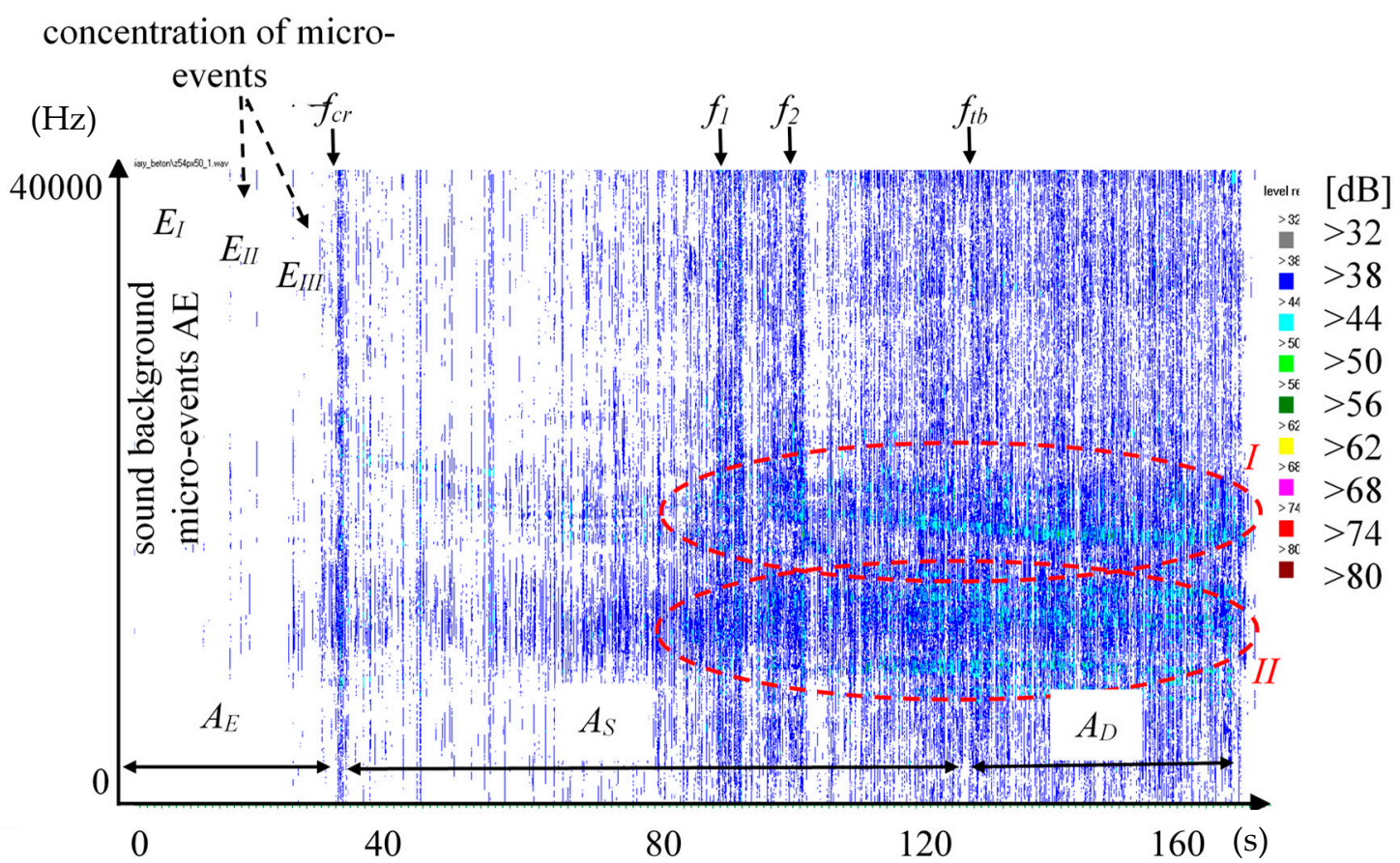

Figure 5. Spectogram of the AE signal.

Figure 6 presents the 2D sound spectra for different AE effects obtained at characteristic points or ranges of events by means of the Audacity program. Event $\mathrm{E}_{0}$ corresponds to the background spectrum. Three characteristic areas were identified: $E_{I}, E_{I I}$ and $E_{I I I}$. Area $E_{I}$ groups single events from $E_{1}$ to $E_{4}$, area $E_{I I}$ includes events from $E_{5}$ to $E_{8}$, and $E_{I I I}$ refers to events from $E_{9}$ to $E_{15}$. The spectra are presented in the wide range of low, medium, and high frequency from $0-45,000 \mathrm{~Hz}$. 

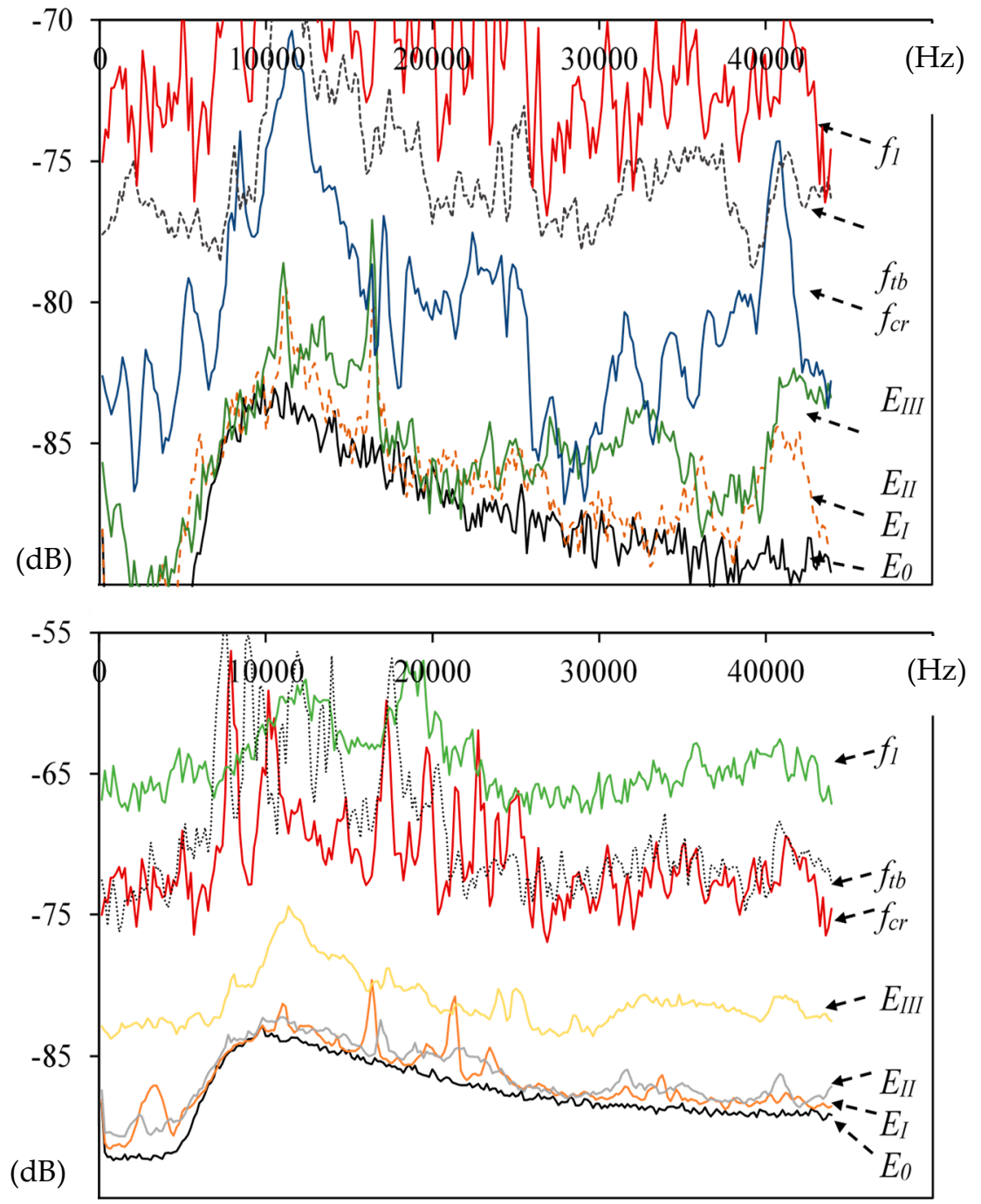

Figure 6. Sound spectra for characteristic events: sound background $\mathrm{E}_{0}$ and ranges of events: $\mathrm{E}_{\mathrm{I}}, \mathrm{E}_{\mathrm{II}}, \mathrm{E}_{\mathrm{III}}$.

Figure 7a,b presents the 3D sound spectra from the Hooke's law range. Figure 7a shows the sound background spectrum and spectra of single AE events (groups of sounds $E_{\mathrm{II}}$ ), with spectra in the time range of 5.4-33 s. Figure $7 \mathrm{~b}$ presents the background spectra, and events spectra $\mathrm{E}_{\mathrm{II}}$ and $\mathrm{E}_{\mathrm{III}}$ in the time range 12.5-39.7 s. Figure 7c displays the background spectra and spectra of multicracking between points $\mathrm{f}_{\mathrm{cr}}$ and $\mathrm{f}_{1}$ in the time range 44.9-70.3 s. Relative amplitudes (of sound intensity components) were analyzed between $50-110 \mathrm{~dB}$. The range of sound intensity components for background spectra and spectra of events $E_{I I}$ was from -110 to $-85 \mathrm{~dB}$, while the group of events $E_{\text {III }}$ and multicracking corresponded to the level of $-80 \mathrm{~dB}$.

Figure $8 \mathrm{a}$ is an image of the sound spectra of the composite: its background, events $\mathrm{E}_{\mathrm{II}}, \mathrm{E}_{\mathrm{III}}$, and the critical point $f_{c r}$. Figure $8 b$ presents the spectra of the area of sudden drops in stress in points $f_{1}$ and $\mathrm{f}_{2}$ in the time range 74.8-102.3 s. Figure $8 \mathrm{c}$ shows the spectra of event in point $\mathrm{f}_{\mathrm{tb}}$ and spectra of the deflection control area. The image is presented in the range 106.3-133.8 s. Relative amplitudes (sound intensity components) were analyzed in the range between 60-120 dB. The range of sound intensity components for background spectra and spectra of events $\mathrm{E}_{\mathrm{II}}$ was from -110 to $-85 \mathrm{~dB}$, while the group of events $\mathrm{E}_{\mathrm{III}}$ and multicracking corresponded to the level of $-80 \mathrm{~dB}$. 
time (s)

(dB)

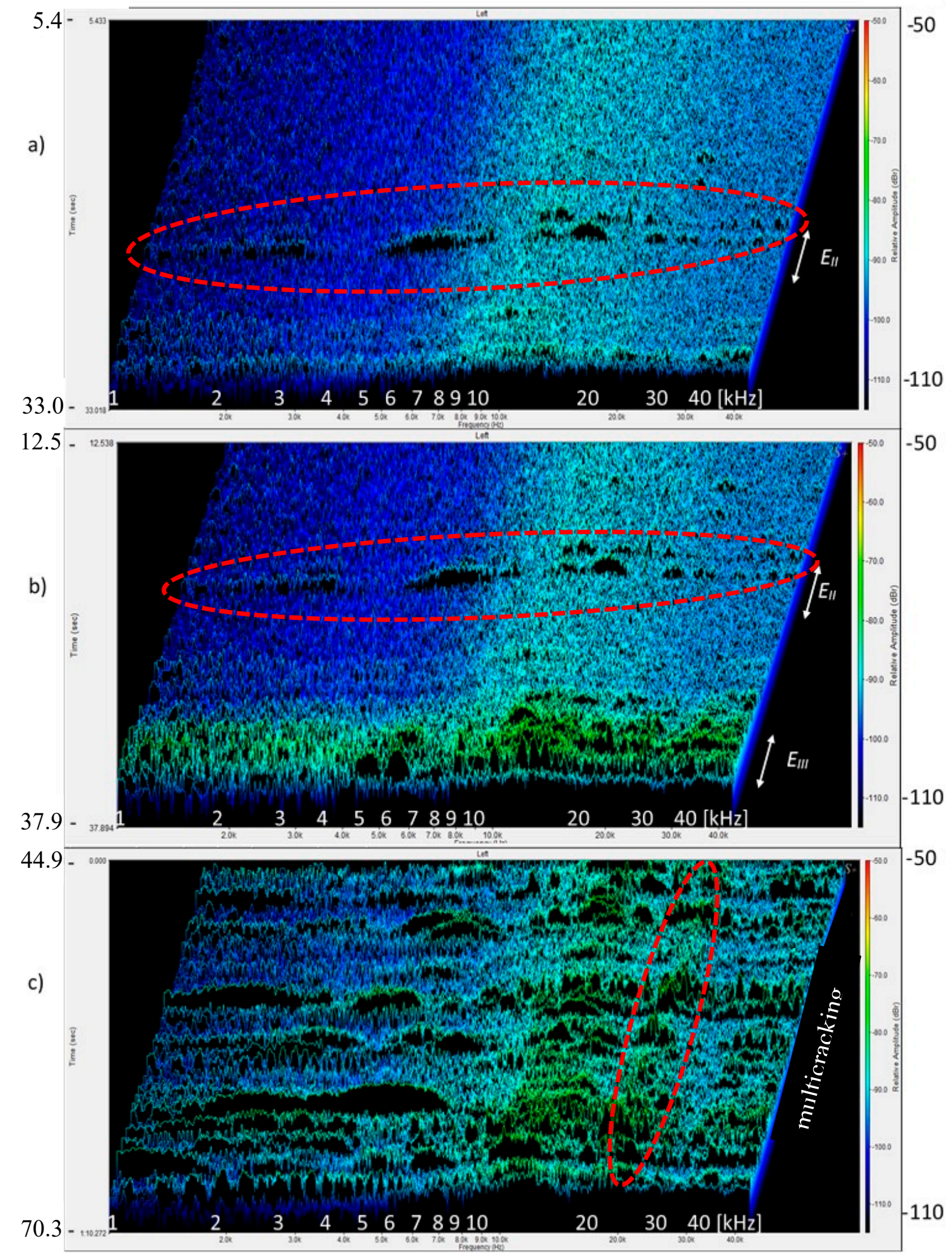

Figure 7. Composite sound spectra: (a) background, micro-events $\mathrm{E}_{\mathrm{II}},(\mathbf{b})$ micro-events $\mathrm{E}_{\mathrm{II}}$ and $\mathrm{E}_{\mathrm{III}}$, (c) multicracking between points $f_{1}$ and $f_{2}$. 
time (s)

$(\mathrm{dB})$

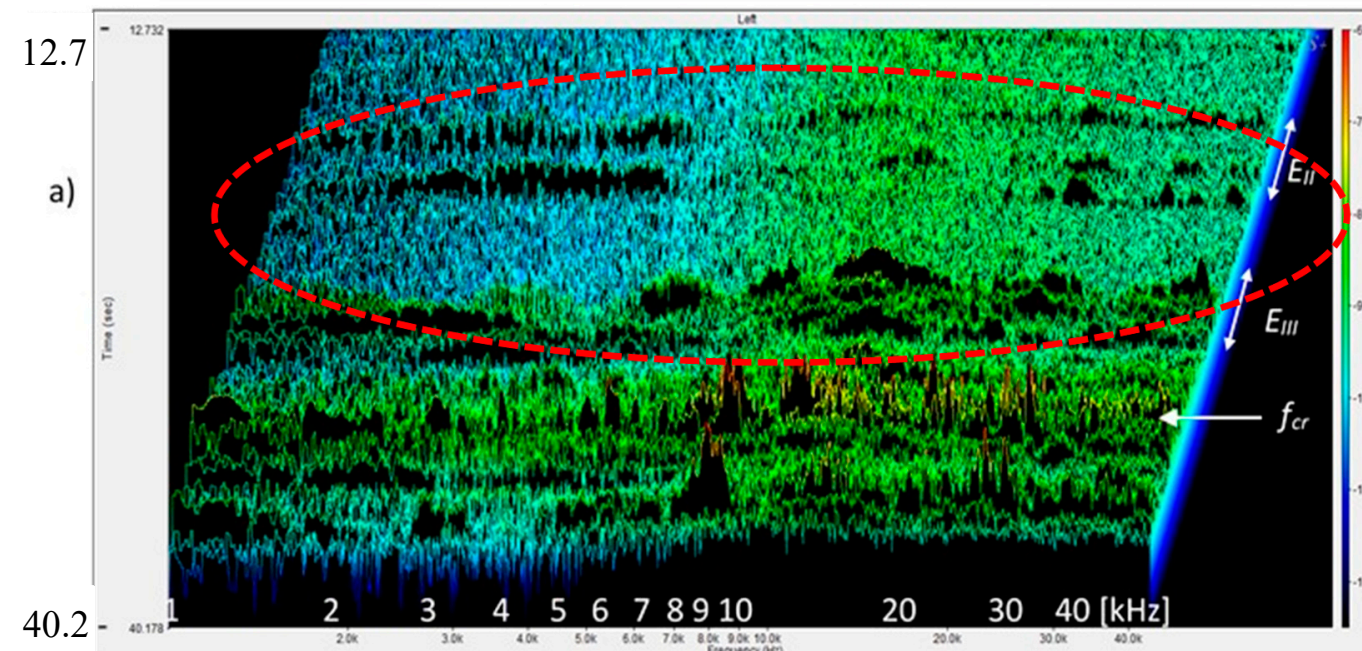

$74.8-$

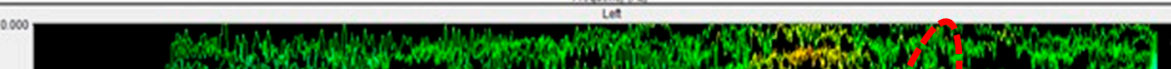

b)

102.3
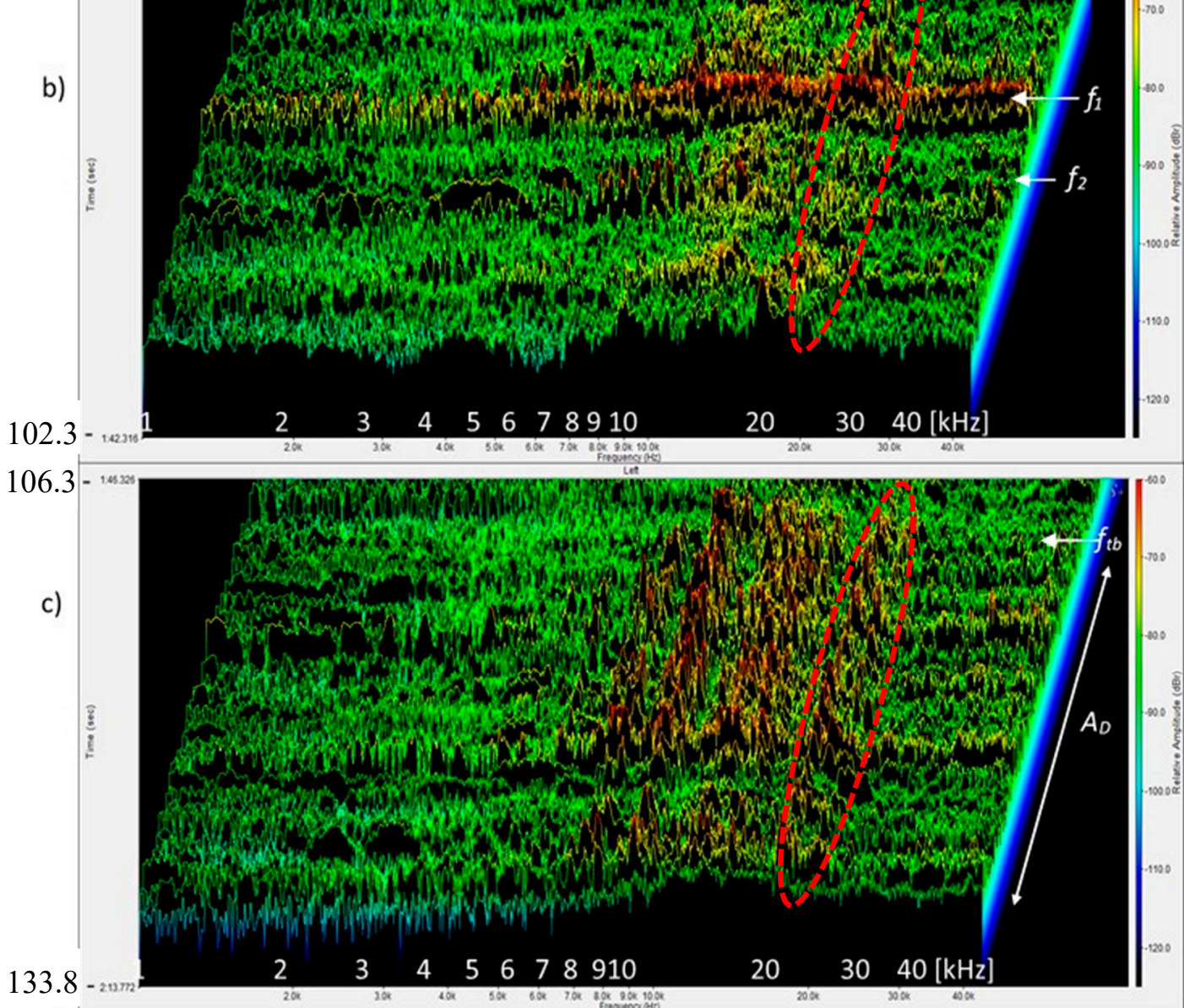

Figure 8. Composite sound spectra: (a) background, micro-events $E_{I I}, E_{I I I}$, and $f_{c}$, (b) event $f_{1}$, (c) event $\mathrm{f}_{\mathrm{tb}}$ and deflection control area $A_{D}$.

\section{Discussion of the Results}

Figure 3 presents force-deflection and force-time correlation obtained during bending-tension tests of a quasi-brittle cement composite with dispersed reinforcement. Presentation of these two charts in one figure enables a better recognition of the destruction processes. The force-deflection curve enables 
the identification of the proportionality, strengthening, deflection control, and crack propagation areas. The sudden decreases in the ability to carry stress that are recorded on the force-deflection curve indicate the appearance of macro-cracks/fractures including fiber breaking.

The force-time curve allows one to indicate the effects occurring at the same time as the recorded AE effects and the AE totals, which should be referred to the force-deflection curve. In order to precisely assess the composite destruction process, it is necessary to correlate both force-deflection and force-time curves with the measured AE effects. The recorded acoustic effects in the proportionality area is presented in 4, Figures $7 \mathrm{~b}$ and $8 \mathrm{a}$. The obtained data indicate the recording of signals and $\mathrm{AE}$ micro events in the proportionality area AE. The measured AE effects have been linked mainly to the sound background signal occurring during the tests and to the occurring events. In the figures, AE events can be observed that have been linked to the individual microcracks occurring within the area of the Hooke's law and micro-regrouping in the structure (micro-relaxation), which do not affect the stress-deflection linear correlation. The occurrence of microcracks before the occurrence of $f_{c r}$, has been confirmed in other publications $[20,26,36]$.

A micro-event precedes the occurrence of critical point $\mathrm{f}_{\mathrm{cr}}$. As shown by Figures 4-8, in the initial period of the operation of Hooke's law, in addition to the background noise, single micro-events/signals appear. The spectra that correspond to sound backgrounds are characterized by the smallest relative amplitude (Figures 6 and 7). Slightly larger intensities of the sound component correspond to micro-events, which do not affect the stress-deflection linear relationship. If the correlating spectra do not occur in groups and there is no increase in sound intensity components, then they may be considered as insignificant (Figure 7a).

The ability to identify them makes it possible to avoid the catastrophic destruction process in traditional cement composites and in quasi-brittle composites to avoid exceeding $\mathrm{f}_{\mathrm{cr}}$. As is shown by the presented data, the sound spectrum corresponding to $f_{\mathrm{cr}}$ is characterized by the largest intensity of the sound spectrum component, which ends the concentration of events (Figures $6 \mathrm{~b}$ and $8 \mathrm{a}$ ).

Recognition of the destruction process by means of the 3D spectrum has already been presented earlier [36] with respect to various cement composites and has also been confirmed in this paper.

What has been observed in this study is a clear division of relative sound amplitudes at the level of circa $7 \mathrm{kHz}$. Medium- and low-frequency sounds are characterized by a lower intensity of sound spectrum component compared to high-frequency sounds.

The analysis of the low-frequency spectra was not clear (it results from the measurement range of the head recording the sound), which is why it was disregarded in the presentation of the 3D image (Figures 7 and 8). The analysis of sound spectra was conducted in the range of $1-40 \mathrm{kHz}$.

After exceeding $\mathrm{f}_{\mathrm{cr}}$, the multicracking effect was observed in the tested composite, resulting in the appearance of the intensities of sound components stronger than the background spectra and single events in the proportionality area, but significantly smaller than the spectrum of $\mathrm{f}_{\mathrm{cr}}$ (Figure $7 \mathrm{c}$ ). The appearance of a macrocrack at point $\mathrm{f}_{\mathrm{tb}}$ and the deflection control process $A_{D}$ resulted in spectra with the sound intensity similar to $\mathrm{f}_{\mathrm{cr}}$ with larger amplitudes in the range of 8-20 kHz (Figures 6-8).

Figure 5 shows a 2D spectrogram that presents the possibility of the identification of destruction processes. It is a method of data imaging used previously by researchers. The obtained image does not show the velocity of increase in the relative amplitudes and contains too large ranges of amplitudes, which may contain various signals, especially those with small amplitudes, which makes it difficult to recognize them (especially with respect to single events and the phenomenon of their concentration). The spectrogram enables the recognition of AE effects with large differences in amplitudes. The use of frequency ranges makes it difficult to identify which area is responsible for the reinforcement breaking, and which is responsible for the pull-out of the reinforcement from the matrix. The 3D sound spectrum contains such information. The spectra responsible for fiber breaking and the occurrence of microcracks are characterized by a course of sharp, high amplitudes in the entire range of the spectrum $1-40 \mathrm{kHz}$ (Figure 8b), whereas the pull-out of fibers and their partial destruction caused an increase in the relative amplitudes, mainly in the area of high frequencies Figure 8c. 
The conducted tests indicate that it is possible to accurately identify the destruction processes in cement composites. It should be emphasised, however, that their correct recognition requires an appropriate correlation of the spectra with the individual micro and macro destruction effects.

\section{Conclusions}

It has been indicated that there is a possibility of predicting the occurrence of $\mathrm{f}_{\mathrm{cr}}$ based on the analysis of sound spectra 3D, the occurring groups of micro-events that precede the end of the load-deflection proportionality area.

The control of micro destruction process before the first crack $f_{c r}$ with the use of acoustic emission (AE) by means of recorded micro-events (increase sumAE) and spectrograms can be used. These analyses should be expanded by adding an interpretation of individual sound spectra (and not the groups of them) and correlated with the load-deflection curve.

The 3D spectra provide a better image of the whole destruction process (particularly with respect to micro-events). The identification of individual events should be correlated with the corresponding individual spectra including the analysis of spectrum in various frequency ranges.

It has been confirmed that the use of spectra with respect to grouped events (destruction processes), in particular in the case of 2D spectra, results in incorrect conclusions if it refers to different events.

Author Contributions: D.L. analyzed the test results and performed editing, prepared the specimens, and analyzed the test results, K.S. conducted the correction of results and applications. All authors have read and agreed to the published version of the manuscript.

Funding: This research received no external funding.

Conflicts of Interest: The authors declare no conflicts of interest.

\section{References}

1. Ohtsu, M. The history and development of acoustic emission in concrete engineering. Mag. Concr. Res. 1996, 48, 321-330. [CrossRef]

2. Dzayea, E.D.; Schutterb, G.D.; Aggelisa, D.G. Monitoring early-age acoustic emission of cement paste and fly ash paste. Cem. Concr. Res. 2020, 129, 105964. [CrossRef]

3. Assi, L.; Soltangharaei, V.; Anay, R.; Ziehl, P.; Matta, F. Unsupervised and supervised pattern recognition of acoustic emission signals during early hydration of Portland cement paste. Cem. Concr. Res. 2018, 103, 216-225. [CrossRef]

4. Brandt, A.M. Fibre reinforced cement-based (FRC) composites after over 40 years of development in building and civil engineering. Compos. Struct. 2008, 86, 3-9. [CrossRef]

5. Kucharska, L.; Brandt, A.M. Pitch-based carbon fibre reinforced cement composites. In Materials Engineering Conference ASCE. Materials for the New Millenium; Chong, K.P., Ed.; ASCE: Washington, DC, USA, 1996; Volume 1, pp. 1271-1280.

6. Logon, D. Monitoring of microcracking effect and crack propagation in cement composites (HPFRC) using the acoustic emission (AE). In Proceedings of the The 7th Youth Symposium on Experimental Solid Mechanics, YSESM ‘08, Wojcieszyce, Poland, 14-17 May 2008.

7. Logon, D. The application of acoustic emission to diagnose the destruction process in FSD cement composites. In Proceedings of the International Symposium on Brittle Matrix Composites BMC-11, Warsaw, Poland, 28-30 September 2015; Andrzej, M., Ed.; Institute of Fundamental Technological Research: Warsaw, Poland, 2015; pp. 299-308.

8. Paul, S.C.; Pirskawetz, S.; Zijl, G.P.A.G.; Schmidt, W. Acoustic emission for characterising the crack propagation in strain-hardening cement-based composites (SHCC). Cem. Concr. Res. 2015, 69, 19-24. [CrossRef]

9. Ranachowski, Z.; Jozwiak-Niedzwiedzka, D.; Brandt, A.M.; Debowski, T. Application of Acoustic Emission Method to Determine Critical Stress in Fibre Reinforced Mortar Beams. Arch. Acoust. 2012, 37, $261-268$. [CrossRef] 
10. Yuyama, S.; Ohtsu, M. Acoustic Emission evaluation in concrete. In Acoustic Emission-Beyond the Millennium; Kishi, T., Ohtsu, M., Yuyama, S., Eds.; Elsevier: Amsterdam, The Netherlands, 2000; pp. 187-213.

11. Kim, B.; Weiss, W.J. Using acoustic emission to quantify damage in restrained fiber-reinforced cement mortars. Cem. Concr. Res. 2003, 33, 207-214. [CrossRef]

12. Reinhardt, H.W.; Weiler, B.; Grosse, C. Nondestructive testing of steel fibre reinforced concrete. Brittle Matrix Compos. 2000, 6, 17-32.

13. Landis, E.; Ballion, L. Experiments to relate acoustic energy to fracture energy of concrete. J. Eng. Mech. 2002, 128, 698-702. [CrossRef]

14. Ouyang, C.S.; Landis, E.; Shh, S.P. Damage assessment in concrete using quantitative acoustic emission. J. Eng. Mech. 1991, 11, 2681-2698. [CrossRef]

15. Chen, B.; Liu, J. Experimental study on AE characteristics of free-point-bending concrete beams. Cem. Concr. Res. 2004, 34, 391-397. [CrossRef]

16. Aggelis, D.G.; Mpalaskas, A.C.; Matikas, T.E. Investigation of different modes in cement-based materials by acoustic emission. Cem. Concr. Res. 2013,48,1-8. [CrossRef]

17. Schabowicz, K.; Gorzelańczyk, T.; Szymków, M. Identification of the degree of fibre-cement boards degradation under the influence of high temperature. Autom. Constr. 2019, 101, 190-198. [CrossRef]

18. Granger, S.; Pijaudier, G.; Loukili, A.; Marlot, D.; Lenain, J.C. Monitoring of cracking and healing in an ultra high performance cementitious material using the time reversal technique. Cem. Concr. Res. 2009, 39, 296-302. [CrossRef]

19. Watanab, K.; Niwa, J.; Iwanami, M.; Yokota, H. Localized failure of concrete in compression identified by AE method. Constr. Build. Mater. 2004, 18, 189-196. [CrossRef]

20. Elaqra, H.; Godin, N.; Peix, G.; R'Mili, M.; Fantozzi, G. Damage evolution analysis in mortar, during compressive loading using acoustic emission and X-ray tomography: Effects of the sand/cement ratio. Cem. Concr. Res. 2007, 37, 703-713. [CrossRef]

21. Shahidan, S.; Rhys Pulin, R.; Bunnori, N.M.; Holford, K.M. Damage classification in reinforced concrete beam by acoustic emission signal analysis. Constr. Build. Mater. 2013, 45, 78-86. [CrossRef]

22. Soulioti, D.; Barkoula, N.M.; Paipetis, A.; Matikas, T.E.; Shiotani, T.; Aggelis, D.G. Acoustic emission behavior of steel fibre reinforced concrete under bending. Constr. Build. Mater. 2009, 23, 3532-3536. [CrossRef]

23. Ohtsu, M. Determination of crack orientation by acoustic emission. Mater. Eval. 1987, 45, 1070-1075.

24. Ohno, K.; Ohtsu, M. Crack classification in concrete based on acoustic emission. Constr. Build. Mater. 2010, 24, 2339-2346. [CrossRef]

25. Ohtsu, M. Elastic wave methods for NDE in concrete based on generalized theory of acoustic emission. Constr. Build. Mater. 2016, 122, 845-855. [CrossRef]

26. Šimonová, H.; Topolář, L.; Schmid, P.; Keršner, Z.; Rovnaník, P. Effect of carbon nanotubes in metakaolin-based geopolymer mortars on fracture toughness parameters and acoustic emission signals. In Proceedings of the BMC 11 International Symposium on Brittle Matrix Composites, Warsaw, Poland, 28-30 September 2015; pp. 261-288.

27. Schabowicz, K.; Gorzelańczyk, T.; Szymków, M. Identification of the degree of degradation of fibre-cement boards exposed to fire by means of the acoustic emission method and artificial neural networks. Materials 2019, 12, 656. [CrossRef]

28. Ranachowski, Z.; Schabowicz, K. The contribution of fibre reinforcement system to the overall toughness of cellulose fibre concrete panels. Constr. Build. Mater. 2017, 156, 1028-1034. [CrossRef]

29. Shiotani, T.; Li, Z.; Yuyama, S.; Ohtsu, M. Application of the AE Improved b-Value to Quantitative Evaluation of Fracture Process. Concr. Mater. J. Acoust. Emiss. 2004, 19, 118-133.

30. Parmar, D. Non-Destructive Bridge Testing and Monitoring with Acoustic Emission (AE) Sensor Technology; Final Report; Hampton University: Hampton, VA, USA, 2011.

31. Ono, K.; Gołaski, L.; Gębski, P. Diagnostic of reinforced concrete bridges by acoustic emission. J. Acoust. Emiss. 2002, 20, 83-98.

32. Van Steen, C.; Verstrynge, E.; Wevers, M.; Vandewalle, L. Assessing the bond behaviour of corroded smooth and ribbed rebars with acoustic emission monitoring. Cem. Concr. Res. 2019, 120, 176-186. [CrossRef]

33. Tsangouri, E.; Michels, L.; El Kadi, M.; Tysmans, T.; Aggelis, D.G. A fundamental investigation of textile reinforced cementitious composites tensile response by Acoustic Emission. Cem. Concr. Res. 2019, 123, 105776. [CrossRef] 
34. Das, A.K.; Suthar, D.; Leung, C.K. Machine learning based crack mode classification from unlabeled acoustic emission waveform features. Cem. Concr. Res. 2019, 121, 42-57. [CrossRef]

35. Logoń, D. FSD cement composites as a substitute for continuous reinforcement. In Proceedings of the Eleventh International Symposium on Brittle Matrix Composites BMC-11, Warsaw, Poland, 28-30 September 2015; Andrzej, M.B., Ed.; Institute of Fundamental Technological Research: Warsaw, Poland, 2015; pp. 251-260.

36. Logon, D. Identification of the Destruction Process in Quasi Brittle Concrete with Dispersed Fibers Based on Acoustic Emission and Sound Spectrum. Materials 2019, 12, 2266. [CrossRef]

37. ASTM 1018. Standard Test Method for Flexural Toughness and First Crack Strength of Fiber-Reinforced Concrete; ASTM: West Conshohocken, PA, USA, 1992; Volume 4.

38. EN 14651. Test Method for Metallic Fibre Concrete. Measuring the Flexural Tensile Strength (Limit of Proportionality (LOP), Residual). 11 July 2005. Available online: https://shop.bsigroup.com/ProductDetail/ ?pid=000000000030160504 (accessed on 6 January 2020).

39. JCI, Japan Concrete Institute Standard. Method of Test for Bending Moment-Curvature Curve of Fiber-Reinforced Cementitious Composites, S-003-2007, 2003. Method of Test for Load-Displacement Curve of Fiber Reinforced Concrete by Use of Notched Beam, 2003. Method of Test for Fracture Energy of Concrete by Use of Notched Beam; Japan Concrete Institute: Tokyo, Japan, 2003.

40. Brandt, A.M.; Ranchowski, Z.; Zieliński, M.; Dąbrowski, M.; Sobczak, M. Report from Tests of Cracking Resistance of Bent Cement Composite Samples; Polish Academy of Science Institute of Fundamental Technology Problems: Warsaw, Poland, 2010.

41. Logon, D.; Schabowicz, K.; Wróblewski, K. Assessment of the mechanical properties of ESD pseudoplastic resins for joints in working elements of concrete structures. Materials 2020, 13, 2426. [CrossRef]

(C) 2020 by the authors. Licensee MDPI, Basel, Switzerland. This article is an open access article distributed under the terms and conditions of the Creative Commons Attribution (CC BY) license (http://creativecommons.org/licenses/by/4.0/). 